\title{
Immunology and Immunotherapy
}

RESEARCH ARTICLE

\section{Rituximab Modifies Peripheral Blood Mononuclear Cells Immune Responses}

\author{
Meir-Djaldetti, MD1, Chyia-Leibovitch, MD², Esther-Ganelin-Cohen, MD, PhD and Hanna-Bessler, \\ $P h D^{1^{*}}$
}

${ }^{1}$ Laboratory for Immunology and Hematology Research, Rabin Medical Center, Hasharon Hospital, The Sackler School of Medicine, Tel-Aviv University, Israel

${ }^{2}$ Institute of Hematology, Davidoff Cancer Center, Rabin Medical Center, The Sackler School of Medicine, Tel-Aviv University, Israel

${ }^{3}$ Institute of Pediatric Neurology, Schneider Children's Medical Center of Israel, The Sackler School of

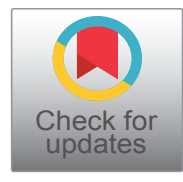
Medicine, Tel-Aviv University, Israel

*Corresponding author: Prof. Hanna Bessler, Laboratory for Immunology and Hematology Research, Rabin Medical Center, Hasharon Hospital, Petah-Tiqva, the Sackler School of Medicine, Tel-Aviv University, 7, Keren Kayemet St, Petah Tiqva, Israel, Tel: 972-3-9372480, Fax: 972-3-9372398

\begin{abstract}
Background: Rituximab, the monoclonal antibody against B lymphocyte protein CD20, is a major asset for treatment of diseases in which B CD20 cells are the foremost etiologic culprit. Based on observations that rituximab is capable to modulate immune responses the question if the drug may affect the capacity of human peripheral blood mononuclear cells (PBMC) for cytokine production was posed.
\end{abstract}

Methods: PBMC were incubated without or with various concentrations of rituximab and the production of TNFa, IL$1 \beta$, IL-6, IFNy, IL-2, IL-1ra and IL-10 was examined using the ELISA method.

Results: While rituximab did not impel non-stimulated PBMC to produce any of the cytokines examined, cells stimulated with PMA/ionomycin expressed a concentration-dependent inhibition of the pro-inflammatory cytokines IL-2 and IFNy. Following LPS stimulation the secretion of TNF $\alpha$ was slightly increased. Notably, the production of the anti-inflammatory cytokine IL-10 was restrained, but at lesser extend in comparison to the effect of rituximab on the pro-inflammatory cytokine secretion.

Conclusions: The results indicate that rituximab in addition to its efficacy as an antibody against CD20 receptor expressing cells, exerts immunomodulatory activity by targeting their capacity for inflammatory cytokine production.

\section{Keywords}

Rituximab, Immunity, Cytokines, Mononuclear cells

\section{Introduction}

The discovery of rituximab, a monoclonal antibody against $B$ lymphocyte membrane protein $C D 20$, contributed greatly to the treatment of B-cell non-Hodgkin's lymphoma and certain autoimmune diseases such as rheumatoid arthritis, myasthenia gravis, primary immune thrombocytopenia and multiple sclerosis [1-4]. Considering the fact that $C D 20$ is expressed on more than $90 \%$ of B non-Hodgkin's lymphoma cells, it is explicable why the combination of rituximab with $\mathrm{CHOP}$, (the classical chemotherapeutic combination of cyclophosphamide, doxorubicin, vincristine and prednisone), possesses greater therapeutic advantage than $\mathrm{CHOP}$ alone $[5,6]$. In a series of 400 elderly patients with diffuse large B-cell lymphoma, those treated with rituximab $+\mathrm{CHOP}$ (R-CHOP) showed an increased release of TNF $\alpha$ and B-cell lysis compared with those treated with $\mathrm{CHOP}$ alone [7]. The main activity of rituximab is expressed by inducing antibody- and complement related cytotoxicity, inhibition of cell proliferation and promotion of apoptosis and phagocytosis [8-10]. The effect of rituximab on the immune cells and its role in $\mathrm{M} 1 / \mathrm{M} 2$ polarization in macrophages from healthy and sick individuals have been previously detailed $[1,11]$. It has been reported that rituximab endorses polarization of pro-inflamma-

Citation: Djaldetti M, Leibovitch C, Ganelin _Cohen E, Bessler H (2019) Rituximab Modifies Peripheral Blood Mononuclear Cells Immune Responses. Int J Immunol Immunother 6:037. doi.org/10.23937/23783672/1410037

Accepted: August 24, 2019: Published: August 26, 2019

Copyright: (c) 2019 Djaldetti M, et al. This is an open-access article distributed under the terms of the Creative Commons Attribution License, which permits unrestricted use, distribution, and reproduction in any medium, provided the original author and source are credited. 
tory $\mathrm{M} 1$ monocytes to the anti-inflammatory $\mathrm{M} 2$ ones leading to a decreased production of pro-inflammatory cytokines, increased generation of the anti-inflammatory IL-10 and waning of inflammation [12]. The modulation of macrophage functions by rituximab explains its beneficial effect in patients with rheumatoid arthritis resistant to conventional therapy $[12,13]$. It is noteworthy that rituximab amplifies the activity of monocytes stimulated with macrophage colony-stimulating factor with a significantly increase in their cytotoxicity [14] directing to an upgraded therapeutic outcome of diseases in which monocytes are the main cohort against B-cells. It is conceivable that rituximab affects CD20 cells by a number of mechanisms including increased cellular senescence and increase of oxygen species [15]. In the present work we sought to investigate the effect of rituximab on the capacity for cytokine production by human peripheral blood mononuclear cells (PBMC).

\section{Materials and Methods}

\section{Cell preparation}

The study was approved by the Ethics Committee of the Rabin Medical Center. Blood bank donors gave written informed consent affirming that components of their blood, not suitable for therapeutic purposes, could be used for medical research. Peripheral blood mononuclear cells (PBMC) were separated from venous blood by Lymphoprep-1077 (Axis-Shield PoC AS, Oslo, Norway) gradient centrifugation. The cells were washed twice in phosphate buffered saline (PBS) and suspended in newborn bovine serum (Biological Industries, Beith Haemek, Israel) containing 10\% DMSO (Sigma, Israel). The cell suspension was aliquoted and stored at $-70{ }^{\circ} \mathrm{C}$ until used. On the day of the assay the cells were quickly thawed and suspended in RPMI-1640 medium (Biological Industries, Beith Haemek, Israel) containing 1\% penicillin, streptomycin nystatin and $10 \%$ fetal bovine serum (FBS), and designated as complete medium (CM).

\section{Rituximab preparation}

Rituximab (MabThera, Hoffmann-La Roche Ltd. Bazel, Switzerland) was dissolved in $0.9 \%$ saline at $10 \mathrm{mg} /$ $\mathrm{ml}$. Further dilutions were made in saline. Rituximab was added at the onset of cell cultures at final concentrations of $125 \mu \mathrm{g} / \mathrm{ml}, 250 \mu \mathrm{g} / \mathrm{ml}$, and $500 \mu \mathrm{g} / \mathrm{ml}$ at a volume of $10 \mu \mathrm{l} / \mathrm{ml}$, amounts extrapolated from those gained by clinical experience [5]. Control cultures contained $10 \mu \mathrm{l} / \mathrm{ml}$ of saline.

\section{Effect of rituximab on cell proliferation}

The effect of rituximabon PBMC proliferation was determined using XTT proliferation assay kit (Biological Industries, Beith Haemek, Israel). In short, $0.1 \mathrm{ml}$ aliquots of PBMC suspended at $10^{5} / \mathrm{ml}$ in CM were seeded at each one of 96 well plates and incubated for $24 \mathrm{hrs}$ in the absence or presence of rituximab added at the onset of cultures at concentrations as indicated. At the end of the incubation period the cells were stained according to the manufacturer's instructions. The plates were incubated for $3 \mathrm{hrs}$ at $37^{\circ} \mathrm{C}$ in a humidified incubator containing $5 \% \mathrm{CO}_{2}$ and the absorbance was measured at $450 \mathrm{~nm}$ using ELISA reader.

\section{Effect of rituximabon cytokine production}

$1.0 \mathrm{ml}$ of PBMC $(2 \times 106 / \mathrm{ml}$ suspended in CM) was incubated without or with LPS $(50 \mathrm{ng} / \mathrm{ml})$ for TNF $\alpha$, IL$1 \beta, I L-6, I L-10$ and IL-1ra production or with PMA $1 \mu \mathrm{g} / \mathrm{ml}$ and ionomycin $0.5 \mu \mathrm{g} / \mathrm{ml}$ for IL-2 and IFN $\gamma$ secretion. The cultures were maintained for $24 \mathrm{hrs}$ at $37^{\circ} \mathrm{C}$ in a humidified atmosphere containing $5 \% \mathrm{CO}_{2}$. At the end of the incubation period the cells were removed by centrifugation at $250 \mathrm{~g}$ for $10 \mathrm{~min}$. , the supernatants were collected and kept at $-70{ }^{\circ} \mathrm{C}$ until assayed for cytokine content.

\section{Cytokine content in the supernatants}

The concentration of TNF $\alpha$, IL-1 $\beta$, IL-6, IFN $\gamma$, IL-10, IL$1 \mathrm{ra}$ and IL-2 in the supernatants was tested using ELISA kits specific for these cytokines (Biosource International, Camarillo, CA) as detailed in the guide-line provided by the manufacturer. The detection levels of these kits were $15 \mathrm{pg} / \mathrm{ml}$ for IL-6 and $30 \mathrm{pg} / \mathrm{ml}$ for the remaining ones.

\section{Statistics}

A linear mixed model with repeated measures and the assumption of compound symmetry (CS) was used to assess the effect of different concentrations of rituximab on cytokine secretion by stimulated and non-stimulated PBMC. SAS vs. 9.4 was used for this analysis. Paired t-test was applied to compare between the level of cytokines produced with various concentrations of rituximab and that present in control cultures. Probability values of $p<0.05$ were considered as significant. The results are expressed as mean \pm SEM of 6 different blood donors.

\section{Results}

\section{Effect of rituximab on cell proliferation}

24 hrs of incubation of PBMC with rituximab at concentrations between 125 and $500 \mu \mathrm{g} / \mathrm{ml}$ did not exert any effect on cell proliferation assessed by XTT test ( $p>0.1$ ) (data not shown).

\section{Effect of rituximab on cytokine production}

TNF $\alpha$ : The production of TNF $\alpha$ by non-stimulated PBMC was not affected by 24 hrs of incubation with rituximab at concentrations between 125 and $500 \mu \mathrm{g} /$ $\mathrm{ml}\left(\mathrm{F}_{3,24}=1.88, \mathrm{p}=0.17\right.$, Figure 1). However, at the same culture conditions, the secretion of TNF $\alpha$ by LPSstimulated PBMC was significantly enhanced $\left(\mathrm{F}_{3,24}=\right.$ $4.82, p=0.015)$, and was elevated by $40 \%$ at 250 and $500 \mu \mathrm{g} / \mathrm{ml}$ of rituximab ( $\mathrm{p}=0.006$, Figure 2$)$. 


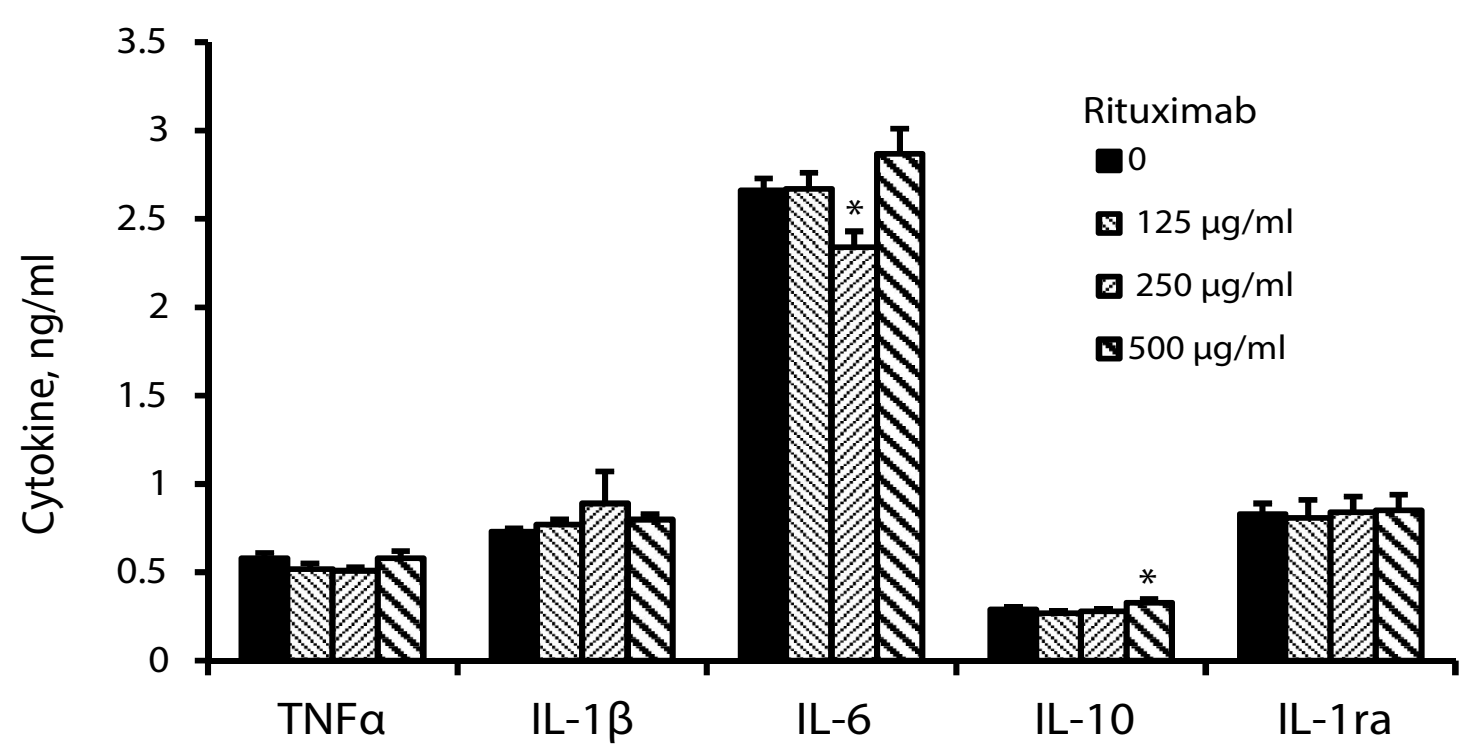

Figure 1: Non-stimulated PBMC were incubated for 24 hrs without $(0)$ or with rituximab at concentrations as indicated. The level of cytokines in the supernatants was tested by ELISA. The results are expressed as Mean \pm SEM of 6 experiments (6 different blood donors). Asterisks represent statistically significant difference from cells incubated without rituximab ( ${ }^{*} P<$ 0.05).

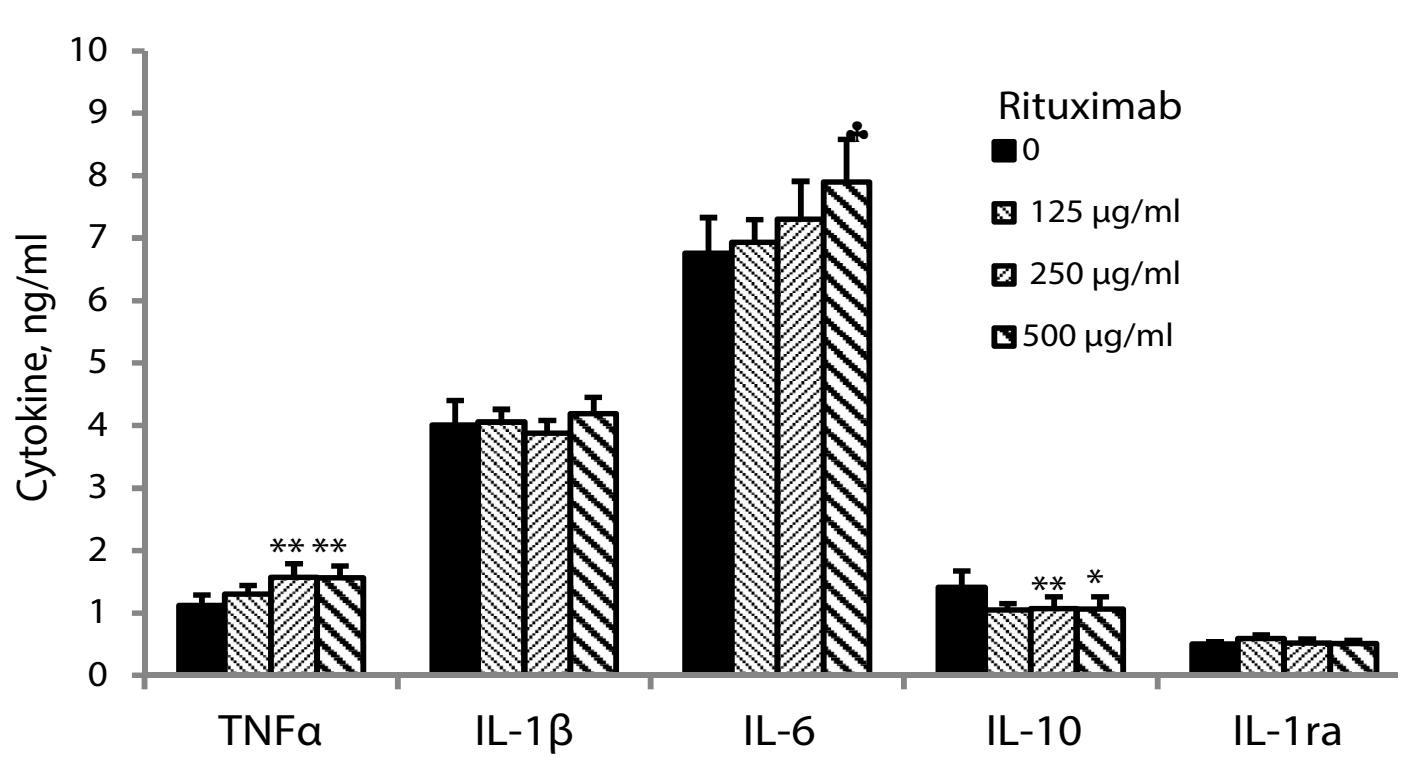

Figure 2: LPS-stimulated PBMC were incubated for 24 hrs without $(0)$ or with rituximab at concentrations as indicated. The level of cytokines in the supernatants was tested by ELISA. The results are expressed as Mean \pm SEM of 6 experiments (6 different blood donors). Asterisks represent statistically significant difference from cells incubated without rituximab ( $\mathrm{P}<$ $0.05 ; "$ * $p<0.01 ; " p=0.059$ ).

IL-1 $\beta$ and IL-6: 24 hrs of incubation of PBMC with rituximab at the above mentioned conditions had no effect on the secretion of IL-1 $\beta$ by non-stimulated $\operatorname{PBMC}\left(\mathrm{F}_{3,24}=1.97, \mathrm{p}=0.16\right.$, Figure 1$)$ or cells stimulated with LPS $\left(F_{3,24}=0.77, p=0.52\right.$, Figure 2). IL-6 secretion by non-stimulated PBMC was slightly reduced upon $24 \mathrm{hrs}$ of incubation with rituximab added at the same concentrations $\left(F_{3,24}=4.15, p=0.025\right)$ and was lowered by $12 \%(p=0.049)$ at $250 \mu \mathrm{g} / \mathrm{ml}$ of the drug (Figure 3 ). The production of IL- 6 by LPS-stimulated PBMC was not affected by incubation with rituximab (Figure 2).
IL-2 and IFN $\gamma$ (Figure 3): No detectable concentrations of IL-2 or IFNY could be found in supernatants of non-stimulated PBMC incubated for 24 hrs without or with the above cited doses of rituximab (data not shown). However, incubation of PMA/ionomycin stimulated PBMC with increased concentrations of rituximab between 125 and $500 \mu \mathrm{g} / \mathrm{ml}$ for $24 \mathrm{hrs}$ caused a concentration-dependent inhibition of IL-2 and IFNY production $\left(F_{3,24}=27.75, p<0.0001\right.$ and $F_{3,24}=9.71, p$ $=0.0008$, respectively). IL-2 secretion was inhibited by $24 \%(p=0.0027)$ and $53 \%(p<0.0001)$ at rituximab concentrations of $250 \mu \mathrm{g} / \mathrm{ml}$ and $500 \mu \mathrm{g} / \mathrm{ml}$, respectively, 


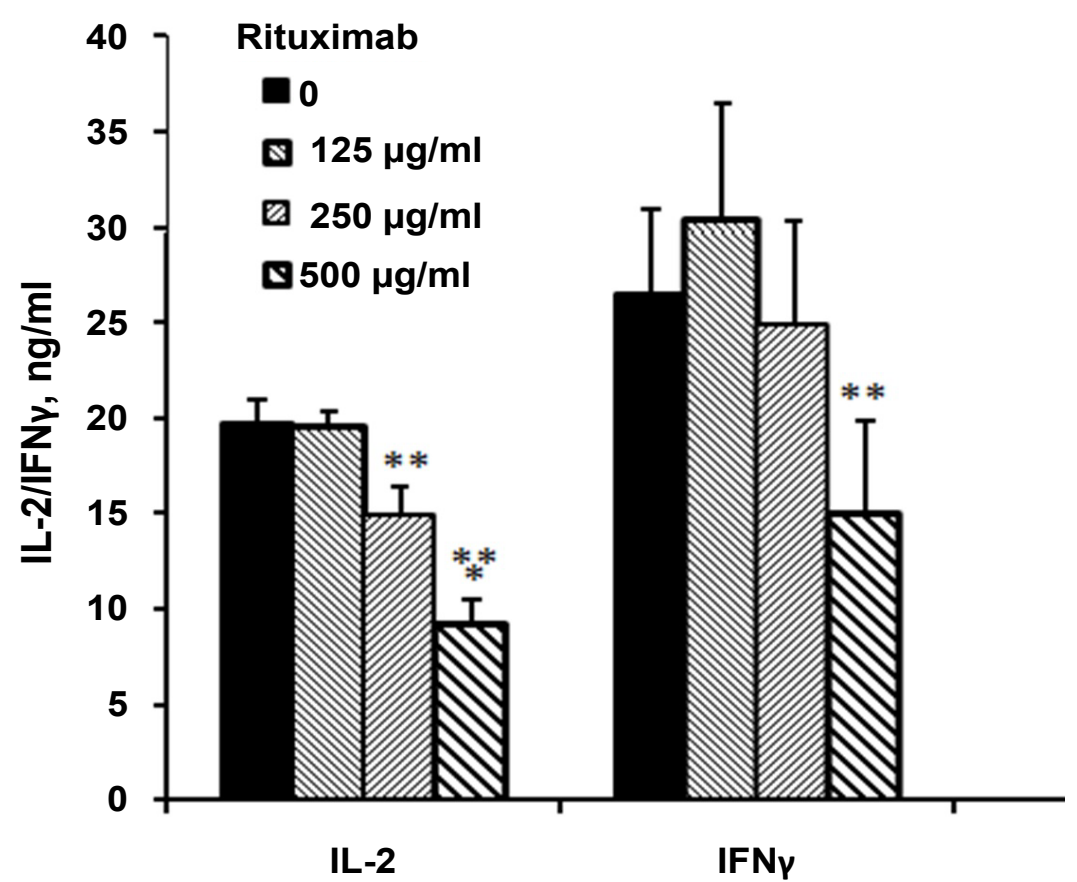

Figure 3: PMA/ionomycin- stimulated PBMC were incubated for $24 \mathrm{hrs}$ without $(0)$ or with rituximab at concentrations as indicated. The level of cytokines in the supernatants was tested by ELISA. The results are expressed as Mean \pm SEM of 6 experiments ( 6 different blood donors). Asterisks represent statistically significant difference from cells incubated without rituximab $\left({ }^{* *} p<0.01 ;{ }^{* * *} p<0.001\right)$.

whereas that of IFN $p$ was lowered by $44 \%(p=0.006)$ at $500 \mu \mathrm{g} / \mathrm{ml}$ of the drug.

IL-10 and IL-1ra: The secretion of IL-10 by non-stimulated PBMC was slightly increased upon incubation with rituximab $\left(F_{3,24}=4.03, p=0.027\right)$ and was higher by $14 \%$ at $500 \mu \mathrm{g} / \mathrm{ml}$ of the drug (Figure 1). Incubation of LPS-stimulated PBMC with rituximab for $24 \mathrm{hrs}$ caused inhibition of IL-10 secretion by $25 \%(p<0.05)$ at the three concentrations applied $\left(F_{3,24}=3.41, p=0.045\right.$, Figure 2). IL-1ra production by non-stimulated or LPS-stimulated PBMC was not affected by $24 \mathrm{hrs}$ of incubation with rituximab at all three concentrations $\left(F_{3,24}=0.18, p\right.$ $=0.9)$ and $\left(F_{3,24}=2.42, p=0.106\right.$, respectively, Figure 1 and Figure 2).

\section{Discussion}

Development of lymphoma may activate patients' immune system. In 60 patients with follicular lymphoma the level of IL-1R1, IL-6, IL-7, IL-10, and TNF- $\alpha$ were found to be elevated compared to matched controls. Those treated with rituximab alone showed increased production of IL-12 and IL-1ra $[16,17]$. The capacity of rituximab to target $B$ cell $C D 20$ receptors explains its property to induce malignant cell depletion in cases of lymphoma and a number of autoimmune diseases. In addition, rituximab activates macrophages for cytokine production. Administration of rituximab may provoke systemic responses associated with increased production of cytokines such as TNF, IL-1, IL- 6 and IFN- $\gamma$ $[18,19]$. CD20 ${ }^{+} \mathrm{T}$ cells produce high level of TNF $\alpha$ and these cells are more affected by rituximab. Therefore, one would expect that the drug will cause reduced se- cretion of this cytokine by LPS stimulated PBMC. However, the results obtained hereby were different. A possible explanation is that in our experimental setup we used a mixture of different types of TNF $\alpha$ producing mononuclear cells in order to mimic the in vivo situation, an item that may affect the results. According to Degboe, et al. [12] rituximab enhances the macrophage anti-inflammatory functions by inhibition of their ability to produce pro-inflammatory cytokines mainly IL-6 and IL-12. Moreover, it has been reported that rituximab affects a subpopulation of $\mathrm{CD}^{+} \mathrm{CD} 2 \mathrm{O}^{+} \mathrm{T}$ cells present predominantly in lymphatic organs and cerebrospinal fluid and are able to produce IL-4, IL-17, IFN $\gamma$ and TNF $\alpha$ [20]. Renal transplanted patients treated with rituximab showed increased expression of IL-10 whereas the secretion of IL-2, IL-4, IL-6, IL-12, IL-17, TGF- $\beta$ and TNF $\alpha$ was not affected [21]. Patients treated with rituximab who showed increased levels of IL-1ra and IL-12 had a shorter disease free survival, suggesting that modulation of cytokine production in these individuals may serve as a prognostic factor [16]. Similar conclusions have been attained by Toubi, et al. [22] who have observed close association between clinical improvement and changes in cytokine production by macrophages of patients with rheumatoid arthritis. Remarkably, lymphoma cells are able to release cytokines, especially IL10 , that are capable to increase macrophage phagocytic capacity towards lymphoma cells opsonized by rituximab [23]. In the present study rituximab did not exert any effect on cytokine production by non-stimulated cells. On the other hand incubation of PMA/ionomycin stimulated PBMC with the drug induced a concentration-dependent inhibited production of IL-2 and IFN- $\gamma$. 
Since not only macrophages are IL-2 producers but also certain types of activated T cells such as $\mathrm{CD} 4^{+}$and $\mathrm{CD}^{+}[24]$, it is conceivable to assume that they possess CD20 receptors targeted by rituximab and providing evidence that rituximab activity extends to cells others than B cells [1]. IFN- $\gamma$ is a pro-inflammatory cytokine produced by activated $\mathrm{CD} 4+, \mathrm{CD} 8+$ and NK cells with an action aimed mainly against macrophages [25]. The inhibited generation of IFN- $\gamma$ by PBMC induced by rituximabin our experimental setup further supports the assumption that not only macrophages, but also other mononuclear cells express CD20 receptors. Considering the role of rituximab in modulation of inflammation by targeting generation of pro-inflammatory cytokines [20] one would expect an increased production of the anti-inflammatory IL-10, following incubation of PBMC with the drug, a result not observed in the present work. One possible explanation could be that in our experiments carried out in vitro there was no effect of rituximab on cell proliferation and therefore the number of IL-10 producing B cells (IL-10+ cells) could not alter, while in patients with autoimmune diseases the extent of IL-10+cells has been found to be repopulated and even elevated several months after administration of the drug [26]. We focused on the effect of rituximab on cell proliferation since cytokine production depends on the cell number. If rituximab would affect cell proliferation one would expect to obtain a decrease in cell number which was not the case. Consequently, if the cell number were affected because of altered cell proliferation under the drug's effect, we should correlate the results according to the cell number. It is plausible to assume that the drug affects cytokine production by PBMC directly and it does not dependent on their quantity. The capacity of rituximab to affect phagocytosis, apoptosis and other cell health markers has been previously reported [8-10].

In short, the results of the study indicate that rituximab applied in vitro exerts a suppressive role on the capacity of peripheral blood mononuclear cells for cytokine production.

\section{Funding}

None.

\section{Acknowledgement}

The authors would like to thank Ms. Tzippy Shochat, MSc, Statistical Consultant, Rabin Medical Center, Beilinson Hospital, for her excellent help in performing the statistical calculations.

\section{References}

1. Marino M, Bartoccioni E, Alboini PE, Evoli A (2018) Rituximab in myasthenia gravis: A "to be or not to be" inhibitor of T cell function. Ann N Y Acad Sci 1413: 41-48.

2. Jones JD, Hamilton BJ, Skopelja S, Rigby WF (2014) Induction of interleukin-6 production by rituximab in human B cells. Arthritis Rheumatol 66: 2938-2946.
3. Gudbrandsdottir S, Brimnes M, Kollgaard T, Hasselbalch HC, Nielsen CH (2018) Effects of rituximab and dexamethasone on regulatory and proinflammatory B-cell subsets in patients with primary immune thrombocytopenia. Eur J Haematol 100: 45-52.

4. Midaglia L, Mora L, Mulero P, Sastre-Garriga J, Montalban $X$ (2018) Rituximab: Its efficacy, effectiveness and safety in the treatment of multiple sclerosis. Rev Neurol 66: 25-32.

5. Plosker GL, Figgitt DP (2003) Rituximab: A review of its use in non-Hodgkin's lymphoma and chronic lymphocytic leukaemia. Drugs 63: 803-843.

6. Engelhard M (2016) Anti-CD20 antibody treatment of nonHodgkin lymphomas. Clin Immunol 172: 101-104.

7. Bienvenu J, Chvetzoff R, Salles G, Balter C, Tilly H, et al. (2001) Tumor necrosis factor alpha release is a major biological event associated with rituximab treatment. Hematol J 2: 378-384.

8. Grillo-Lopez AJ, White CA, Varns C, Shen D, Wei A, et al. (1999) Overview of the clinical development of rituximab: First monoclonal antibody approved for the treatment of lymphoma. Semin Oncol 66-73.

9. Salles G, Barrett M, Foa R, Maurer J, O'Brien S, et al. (2017) Rituximab in B-Cell hematologic malignancies: A review of 20 years of clinical experience. Adv Ther 34: 2232-2273.

10. Maloney DG (2001) Mechanism of action of rituximab. Anticancer Drugs 2: S1-S4.

11. Shapouri-Moghaddam A, Mohammadian S, Vazini $H$, Taghadosi M, Esmaeili SA, et al. (2018) Macrophage plasticity, polarization, and function in health and disease. $J$ Cell Physiol 233: 6425-6440.

12. Degboe $Y$, Rauwel B, Baron M, Boyer JF, Ruyssen-Witrand A, et al. (2019) Polarization of rheumatoid macrophages by TNF targeting through an IL-10/STAT3 mechanism. Front Immunol 18.

13. Dass S, Vital EM, Emery P (2006) Rituximab: Novel B-cell depletion therapy for the treatment of rheumatoid arthritis. Expert Opin Pharmacother 7: 2559-2570.

14. Shimadoi S, Takami A, Kondo $Y$, Okumura H, Nakao S (2007) Macrophage colony-stimulating factor enhances rituximab-dependent cellular cytotoxicity by monocytes. Cancer Sci 98: 1368-1372.

15. Dabritz JH, Yu Y, Milanovic M, Schonlein M, Rosenfeldt MT, et al. (2016) CD20-targeting immunotherapy promotes cellular senescence in B-cell lymphoma. Mol Cancer Ther 15: 1074-1081.

16. Mir MA, Maurer MJ, Ziesmer SC, Slager SL, Habermann T, et al. (2015) Elevated serum levels of IL-2R, IL-1RA, and CXCL9 are associated with a poor prognosis in follicular lymphoma. Blood 125: 992-998.

17. Kimby E (2015) Serumcytokines in follicular lymphoma. Blood 125: 892-893.

18. Winkler U, Jensen M, Manzke O, Schulz H, Diehl V, et al. (1999) Cytokine-release syndrome in patients with B-cell chronic lymphocytic leukemia and high lymphocyte counts after treatment with an anti-CD20 monoclonal antibody (rituximab, IDEC-C2B8). Blood 94: 2217-2224.

19. Agarwal A, Vieira CA, Book BK, Sidner RA, Fineberg NS, et al. (2004) Rituximab, anti-CD20, induces in vivo cytokine release but does not impair ex vivo T-cell responses. Am J Transplant 4: 1357-1360.

20. Schuh E, Berer K, Mulazzani M, Feil K, Meinl I, et al. (2016) 
Features of human CD3+CD20+ T cells. J Immunol 197: 1111-1117.

21. Kamburova EG, van den Hoogen MW, Koenen HJ, Baas MC, Hilbrands LB, et al. (2015) Cytokine release after treatment with rituximab in renal transplant recipients. Transplantation 99: 1907-1911.

22. Toubi E, Kessel A, Slobodin G, Boulman N, Pavlotzky E, et al. (2007) Changes in macrophage function after rituximab treatment in patients with rheumatoid arthritis. Ann Rheum Dis 66: $818-820$.

23. Leidi M, Gotti E, Bologna L, Miranda E, Rimoldi M, et al (2009) M2 macrophages phagocytose rituximab-opsonized leukemic targets more efficiently than $\mathrm{m} 1$ cells in vitro. $\mathrm{J}$ Immunol 182: 4415-4422.

24. Liao W, Lin JX Leonard WJ (2011) IL-2 family cytokines: New insights into the complex roles of IL-2 as a broad regulator of $T$ helper cell differentiation. Curr Opin Immunol 23: $598-604$

25. Resende M, Cardoso MS, Ribeiro AR, Florido M, Borges $M$, et al. (2017) Innate IFN-y-producing cells developing in the absence of IL-2 receptor common $\mathrm{Y}$-chain. J Immunol 199: 1429-1439.

26. Hofmann K, Clauder AK, Manz RA (2018) Targeting B cells and plasma cells in autoimmune diseases. Front Immunol 23. 